\title{
INVESTIGACIÓN
}

Recibido: 10/02/2020 --- Aceptado: 02/04/2020 --- Publicado: 15/12/2020

\section{LA NECESIDAD DE LA EDUCACIÓN ESTÉTICA PARA LA FORMACIÓN EN DISEÑO GRÁFICO: UNA PROPUESTA METODOLÓGICA}

\section{The need for aesthetic education for training in graphic design: a methodological proposal}

África Presol Herrero ${ }^{1}$ : Universidad Antonio de Nebrija. España.

apresol@nebrija.es

Julio Pérez Manzanares: Universidad Antonio de Nebrija. España. jperezman@nebrija.es

\section{RESUMEN}

Esta investigación estudia la necesidad de combinar la educación estética y la adquisición de cultura visual como aptitudes técnicas para el diseño gráfico. Se establece una metodología doble: recuperación y exploración bibliográfica que analiza la vinculación de los conocimientos de carácter técnico de ambas disciplinas, así como del análisis práctico de los resultados obtenidos mediante su aplicación en la experiencia docente y el cuestionario como técnica de investigación cualitativa realizado a estudiantes del Grado en Publicidad y Relaciones Públicas en Educación Superior. Los resultados muestran que el método de enseñanza transversal y una formación de carácter histórico y teórico sobre los medios visuales es adecuado para la aplicación de técnicas digitales y el desarrollo de proyectos de creación de branding, identidad visual e imagen de marca.

PALABRAS CLAVE: Diseño gráfico - Estética - Cultura visual - Comunicación Branding - Identidad Visual

\section{ABSTRACT}

This research studies the need to combine aesthetic education and the acquisition of visual culture as technical skills for graphic design. A double methodology is established: recovery and bibliographic exploration that analyzes the linking of the technical knowledge of both disciplines, as well as the practical analysis of the results

\footnotetext{
${ }^{1}$ África Presol Herrero: Doctora en Publicidad y Relaciones Públicas (UCJC). Licenciada en Ciencias de la Información (UCM). Directora del Grado en Publicidad y RR.PP. de la Facultad de Comunicación y Artes UAN. Especialista en Tecnologías Digitales e innovación docente.
} 
Presol Herrero, A. y Pérez Manzanares, J.

La necesidad de la educación estética para la formación en diseño gráfico: una propuesta metodológica.

obtained through its application in the teaching experience and the questionnaire as a qualitative research technique carried out to Degree students in Advertising and Public Relations. The results show that the transversal teaching method and a historical and theoretical training on visual media is suitable for the application of digital techniques and the development of projects for the creation of branding, visual identity and brand image.

KEY WORDS: Graphic Design - Aesthetics - Visual Culture - Communication Branding - Visual Identity

\section{A NECESSIDADE DA EDUCAÇÃO ESTÉTICA PARA A FORMAÇÃO EM DESIGN GRÁFICO: UMA PROPOSTA METODOLÓGICA}

\section{RESUMO}

Esta pesquisa estuda a necessidade de combinar a educação estética e a aquisição de cultura visual como aptidões técnicas para o design gráfico. Se estabelece uma metodologia dupla: recuperação e pesquisa bibliográfica que analisa a vinculação dos conhecimentos de caráter técnico de ambas disciplinas, assim como a análise prática dos resultados obtidos pela aplicação na experiência docente e o questionário como técnica de pesquisa qualitativa realizada a estudantes da Graduação em Publicidade e Relações Públicas na Educação Superior. Os resultados mostram que o método de ensino transversal e uma formação de caráter histórico e teórico sobre os meios visuais é adequado para a aplicação de técnicas digitais e o desenvolvimento de projetos de criação de branding, identidade visual e imagem de marca.

PALAVRAS CHAVE: Design gráfico - Estética - Cultura visual - Comunicação Branding - Identidade Visual

\section{Como citar el artículo:}

Presol Herrero, A. y Pérez Manzanares, J. (2020). La necesidad de la educación estética para la formación en diseño gráfico: una propuesta metodológica. [The need for aesthetic education for training in graphic design: a methodological proposal].Vivat Academia. Revista de Comunicación, 153, 117-136. doi: https://doi.org/10.15178/va.2020.153.117-136 Recuperado de

http://www.vivatacademia.net/index.php/vivat/article/view/1218

\section{INTRODUCCIÓN}

La necesidad de adecuación de la formación a los desafíos contemporáneos obliga a las distintas materias y especializaciones profesionales a encontrarse en permanente cambio, redefinición y autoevaluación. Partiendo de la hipótesis de la necesidad de incorporar y vincular las materias de Estética y Cultura Visual y las de Diseño Gráfico, los autores han realizado una evaluación de los requerimientos para 
Presol Herrero, A. y Pérez Manzanares, J.

La necesidad de la educación estética para la formación en diseño gráfico: una propuesta metodológica.

su correcta adecuación al programa formativo, una puesta en marcha de las competencias relacionadas con cada una de las materias entre si, y una valoración de los resultados obtenidos.

Como resultado de la investigación de carácter práctico, surge la reflexión que da lugar al presente trabajo de investigación. El mismo, antes de perfilarse como una conclusión definitiva, se propone como un campo ampliado de investigación acerca de la necesidad de reunión de competencias entre materias teóricas y prácticas en el ámbito de la comunicación audiovisual y el diseño gráfico.

El origen de esta investigación se encuentra en la percepción, fruto de la práctica profesional en experiencias de desarrollo formativo en cursos anteriores, de la necesidad de incidir en una mayor formación de carácter histórico, teórico y crítico sobre las nociones estéticas y vinculadas con la cultura visual contemporánea. Por medio del desarrollo de esta materia de conocimiento y sus competencias teóricas y prácticas, se plantea la posibilidad de incidir en una sustancial y exponencial mejora en el desarrollo de los contenidos y el aprendizaje de las competencias estéticas.

El propósito de la revisión de los estudios, refiere la redefinición de competencias y habilidades para los nuevos perfiles profesionales que demanda el mercado. Se ha detectado que una de las principales debilidades de los estudiantes, es la escasez de referencias visuales y tendencias artísticas y creativas que sirvan para desarrollar un sentido de la estética para aplicar en sus comunicaciones y saber aplicar la capacidad de seducción de la publicidad. Los valores estéticos permiten el desarrollo de su capacidad de reflexión y análisis, potenciando la capacidad creativa y la resolución de problemas desde la innovación y el valor diferencial.

Se detecta la necesidad de una formación visual de carácter estético que pudiera adaptarse a la adquisición de nuevos conocimientos, así como desarrollar un pensamiento crítico frente a los diferentes fenómenos visuales vinculados a los ámbitos comunicativos de carácter visual relacionados con la publicidad y el diseño, asi como con múltiples aspectos de carácter ético y deontológico con los que la publicidad, tal y como Pellicer y Parra (2015; 88-124) han puesto en evidencia, comparte con la disciplina filosófica, especialmente en sus aspectos comunicativos y estéticos.

La puesta a prueba de esta modificación mediante la experiencia docente de los autores obligaba, además, a que la misma se realizara desde distintos enfoques. En primer lugar, desde las propias estructuras académicas, teniendo en cuenta el desarrollo de perfiles orientados al presente y el futuro de profesionales del sector. En segundo lugar, desde la propia práctica profesional de los autores como encargados del desarrollo académico de las materias, y cuya trayectoria y metodología docente resultaban fundamentales para la correcta implantación y transmisión de los contenidos metodológicos, críticos y profesionales a implantar en el grado, constituyendo una modificación a evaluar con visos de desarrollo futuro y mejora en virtud de su implantación permanente. 
Presol Herrero, A. y Pérez Manzanares, J.

La necesidad de la educación estética para la formación en diseño gráfico: una propuesta metodológica.

Estas incorporaciones venían predestinadas por dos cuestiones básicas, que trataremos de contextualizar en el estudio de antecedentes, acerca de la pertinencia de elaboración de una adaptación curricular cuyos contenidos debían ser, vinculando las asignaturas de Estética y Cultura Visual y Diseño Gráfico.

\section{OBJETIVOS}

El estudio pretende ser un avance aplicado de investigación e innovación en la docencia. Basándose en un proceso de aprendizaje en el que se pretende la modificación de la conducta de los sujetos durante el proceso de aprendizaje, que conlleva una modificación de la conducta debido a la interacción con el ambiente (Skowronek, 1970), tratándose de una aprendizaje en el que se produce la modificación de la conducta de las personas que entran en contacto con el conocimiento, con independencia de la experiencia, movido por la interacción con el ambiente. Este proceso puede dividirse en tres dimensiones: contenido, metodología y medios. De la relación entre los contenidos y el alumno, se produce una tensión que se resuelve en la modificación de la conducta. En el "encuentro" (Klafki, 1963) se producen momentos de asimilación de contenidos y experiencias con el resultado de una relación entre el sujeto y el objeto, llenándole de valores y consiguiendo un cambio de comportamiento. Se trata de la "experiencia del cambio" a través del conocimiento, en el que la cultura visual, el arte de la palabras y de la imágenes, proponen que la conducta inicial del sujeto (alumno), junto con el desarrollo de las dimensiones del proceso de aprendizaje, favorezcan una conducta final diferente en el estudiante.

Los objetivos de aprendizaje son metas propuestas por el propio sujeto, autodidácticos y resultado de la planificación de la actividad docente determinada por una conducta deseada e ideada en el alumno, conducta final diseñada de manera aniticipada por los profesores.

Esta investigación desarrolla una metodología medida en tiempo (octubre febrero), con un contenido de aprendizaje concreto para poder aplicar las técnicas de enseñanza y aprendizaje (Adobe) en un medio (digital), con cierta libertad (interacción) y que finaliza con la justificación, el sentido, la propuesta de valor que a partir del conocimiento, promuve al cambio en la respuesta del alumno hacia el mensaje. Por su parte, planificar didácticamente por objetivos favorece los intereses de los alumnos, imponiendo ciertas técnicas de realización del proceso de aprendizaje. La propuesta garantiza la planificación de la enseñanza de acuerdo a los objetivos, pero respetando los valores de los alumnos en el contenido.

La eficacia de la enseñanza por objetivos maximiza los resultados que reconocen la conducta esperada por una planificación exacta de la actividades y su aprovechamiento, en la que los alumnos deberán mostrar el aprendizaje esperado. Por parte del profesor, esta enseñanza ha permitido comprobar y poder corregir la 
Presol Herrero, A. y Pérez Manzanares, J.

La necesidad de la educación estética para la formación en diseño gráfico: una propuesta metodológica.

instrucción en su conjunto, en concreto el trabajo del profesor-alumno, permitiendo una revisión constante de los planes de enseñanza.

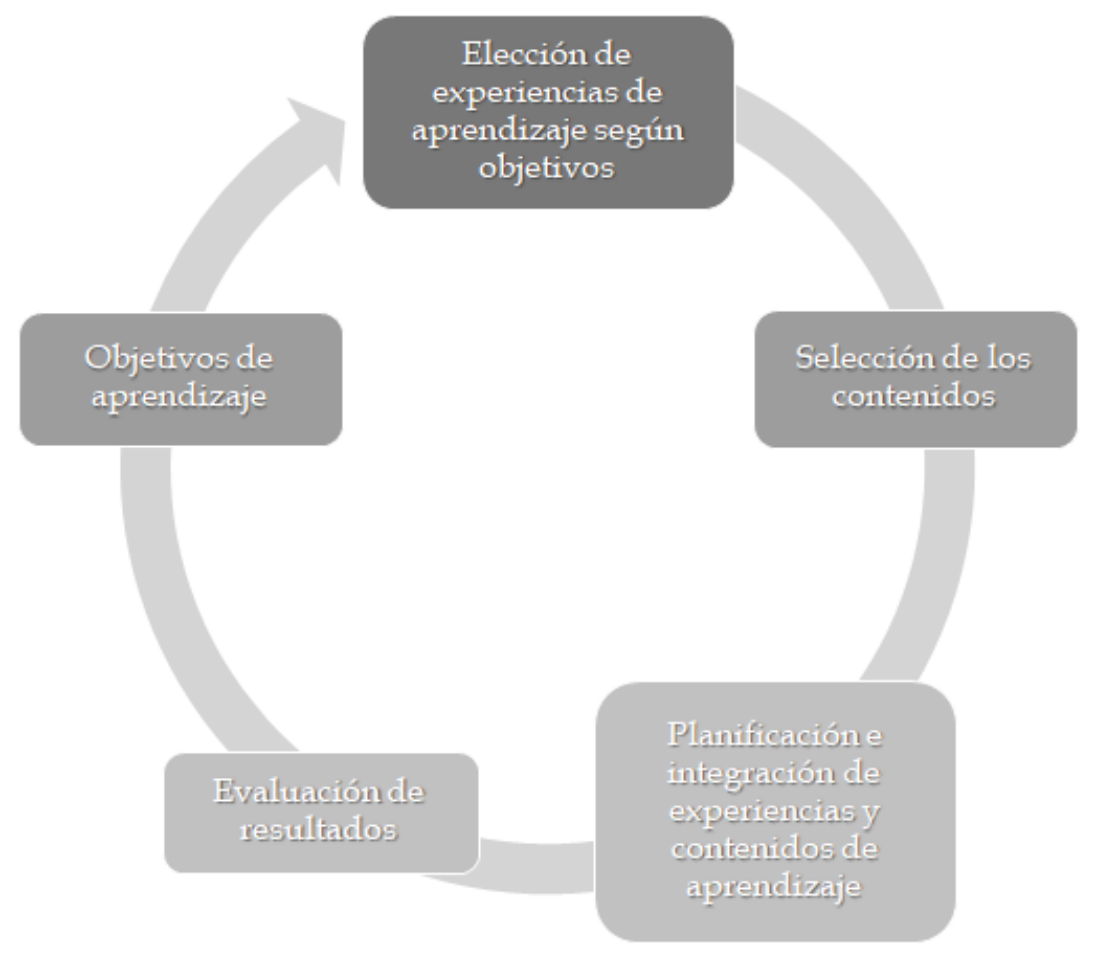

Figura XX. Proceso de curriculum según Wheeler.

Fuente: Elaboración propia

La imagen y la aplicación de metodologías transversales ofrecidas desde la propia formación de los alumnos, con una metodología de trabajo elaborada para evitar la percepción de las diferentes materias como compartimentos estancos entre sí. Se trata que comprendan el proceso desde la formación y adquisición de conocimientos, la fluidez de las distintas esferas de profesionalización y el trabajo como parte indispensable de los nuevos modos y equipos de trabajo.

Destacar la relevancia de la necesidad de habilitar al alumno y dotarle de los recursos necesarios que le permitan identificar las referencias visuales, tanto en tendencias artísticas como creativas, y que sirvan para desarrollar un sentido de la estética para aplicar en piezas comunicativas propias. En concretom la asignatura de Estética persigue dotar al alumnos de la capacidad de aplicar un razonamiento crítico a partir del uso del análisis y la síntesis y, sobre todo, que la capacidad de sensibilizarse acerca del concepto de cultura visual para su desarrollo analítico y reflexivo.

Desde el inicio de su formación, se pretende conseguir una proyección de futuro profesional, que permita habilitar para la interpretación, desde el inicio de su 
Presol Herrero, A. y Pérez Manzanares, J.

La necesidad de la educación estética para la formación en diseño gráfico: una propuesta metodológica.

formación superior, adquiriendo algunas de las estructuras y métodos de trabajo inter y multidisciplinar, es decir, las herramientas de utilidad para su formación y experiencia visual actual, tratando de potenciar no sólo los perfiles profesionales, sino la necesidad de combinación de los mismos con una formación de carácter humanista. La comprensión por parte de los alumnos de la importancia del mundo visual como método de comunicación principal de la cultura contemporánea, y la asunción de patrones críticos de discriminación y análisis de las distintas esferas de lo visual en la cultura contemporánea.

La investigación propone a partir de la experiencia y el análisis, un modelo de equiparación y contribución de modelos educativos, de manera que pueda ser extrapolable a toda formación, especialmente en el ámbito de las humanidades. Sigiendo los propósitos de unificación de enseñanzas teóricas y prácticas en el campo de la formación superior, se ha tartado de desarrollar una serie de contenidos intracurriculares, marcando la necesidad e interdependencia de los mismos y entre si no sólo respecto al resto de enseñanzas regladas dentro del propio grado, sino de manera que los estudiantes puedan percibir la vinculación que su trabajo va a tener y tiene con disciplinas que van más allá de la propia titulación.

En este sentido, el carácter de la enseñanza en cultura visual parece especialmente relevante, por las necesarias interconexiones que establece respecto a disciplinas tecnológicas, sociológicas, psicológicas e incluso legales (Kavin, T. 2009; 20 y ss). Se ha tratado de proponer y transmitir no sólo una determinada destreza profesional, sino la lógica subyacente a esa propia habilidad, extrapolable tanto a la formación como al desarrollo profesional y personal de los alumnos.

Con el fin de comprobar inicialmente la eficacia de estos primeros objetivos a conseguir en el período de evaluación, se ha utilizado la realización y análisis de encuestas anónimas por parte de los alumnos del curso. Las mismas han podido servir a los responsables de la investigación y de las respectivas materias como respuesta y contraste de las decisiones y métodos empleados en la implantación de estas asignaturas, así como de posible constatación, previa evaluación técnica, de la pertinencia de las novedades académicas elaboradas.

\section{MARCO TEÓRICO}

Mencionado ya como propósito de la presente adaptación curricular, en el momento de tomar la decisión de implementar y modificar las asignaturas de grado, introduciendo y vinculando las asignaturas de Estética y Cultura Visual y Diseño Gráfico en el primer curso del grado en Publicidad y Relaciones públicas, se valoraron aspectos que justificaban su idoneidad.

\section{Perfiles y competencias de comunicación}

Con el propósito de determinar la evolución de los estudios en el área de la Comunicación, el estudio RESET de Agencias de España (Reset, 2018), revela que los 
Presol Herrero, A. y Pérez Manzanares, J.

La necesidad de la educación estética para la formación en diseño gráfico: una propuesta metodológica.

perfiles profesionales que van a ser más demandados por las agencias de publicidad, serán los especialistas en Data Analysis y planners estratégicos. Además, entre las capacidades perseguidas destacarán el pensamiento estratégico, la innovación, la capacidad de adaptación así como las habilidades comunicativas.

Por otra parte, entre las habilidades más demandadas se encuentra la Publicidad digital $(27 \%)$, la gestión y creación de contenidos (23\%), las estrategias de contenidos (20\%), las habilidades de comunicación y la capacidad para resolver problemas. (Estudio de la compañía McKinley Marketing Partners, 2018).

Los estudios muestran como los nuevos perfiles profesionales deberán conocer las formas que tiene el consumidor de vivir la publicidad y su relación con las marcas. Incluso, las agencias y las consultoras deben desarrollar su capacidad de pensamiento y de ejecución, con perfiles por áreas de especialización (thinkers y doers). Con el propósito de conseguir ser desarrolladores, con la capacidad de observación y análisis para poder estructurar de manera lógica los contenidos. Parece que el posicionamiento tradicional de la consultora ha mutado (Fernando Polo, Good Rebels 2015).

Con el fin de entender el panorama actual de la situación de la comunicación a nivel internacional, se ha analizado la actividad de algunas de las mejores agencias de publicidad del mundo. Según el primer índice global de excelencia "Best os the best" de WARC que suma los resultados de tres Rankings Creative 100, Effective 100 y Media 100, afirma que entre las mejores agencias destacan BBDO, Nueva York; adam y eveDDB, Londres; McCann, Nueva York. La observación de su actividad gira en torno a la idea de negocio, con el valor de "Brand" como epicentro de todas las campañas de comunicación integradas y de marketing en las que se desarrollan acciones de marketing, diseño de marca y construcción de identidad, estrategias de social media, estrategia de marca, campañas integradas, desarrollo de app mobile y website design, entre otros.

\section{La industria publicitaria en la sociedad visual.}

Tal y como menciona Mirzoeff $(2003 ; 17)$ en su Introducción a la cultura visual, todo ocurre hoy en día en las pantallas. La sociedad digital y la cultura actual de la imagen ha propiciado que la importancia y preeminencia de los lenguajes audiovisuales sean fundamentales en la formación audiovisual. El proceso, a menudo analizado como "estetización del mundo", según autores como Lipovetsky y Serroy (2015), no sólo ha transformado el propio modo de usar la imagen a través de los diversos métodos y medios de comunicación digital (Instagram, gifs, meme), sino que ha cambiado la propia gramática visual.

Como ya intuía el filósofo Vilem Flusser (2019; 79 y ss) a finales de los años ochenta, en los inicios de la denominada posmodernidad en torno al cambio de paradigma visual y el desarrollo de la imagen técnica, el momento actual requiere una nueva formación en torno al aprendizaje y uso de la información visual. 
Presol Herrero, A. y Pérez Manzanares, J.

La necesidad de la educación estética para la formación en diseño gráfico: una propuesta metodológica.

Actualmente, no nos movemos en un universo de nuevas formas de "imaginación", sino en un universo de creación de imágenes técnicas. Esto es: una nueva forma de creación y distribución de mensajes de carácter audiovisual que no son exclusivamente codificadas por sus productores, sino que deben ajustarse a las predeterminaciones, entre otros, de los programas de creación audiovisual, y a los nuevos medios y cauces de transmisión.

Esto provoca una necesidad de control por parte de los actuales creadores audiovisuales y diseñadores, y la obligación de conocer y controlar el manejo y funcionamiento de las imágenes y los mensajes e informaciones comunicativas que portan no sólo antes de su creación, sino teniendo en cuenta, además, la deriva posterior que tendrán en la actual "iconosfera", tal y como ha sido definida por autores como Franco "Bifo" Berardi en sus análisis sobre la que denomina como "iconocracia" contemporánea, o reinado de la cultura visual a través de la que se recibe el mayor número de mensajes a lo largo del día a día (Berardi, 2017; 49 y ss).

Los cambios en el modo de relacionarnos con las imágenes en la cultura actual, obligan a su vez no sólo a que se hayan producido profundos cambios en los métodos de análisis e investigación sobre la misma, tal y como analiza Martínez Luna (2019, 101 y ss) en su obra sobre la cultura visual, sino que, de manera muy específica, obliga a variar los métodos formativos de aquellos profesionales que vayan a utilizar las imágenes como creadoras de contenidos y medio de comunicación. El fin de esta educación visual compartida con prácticas como el diseño y la publicidad, asegura que los profesionales gocen de la suficiente formación en análisis y características de las mismas como para realizar lo que podríamos denominar como un "uso responsable" de las mismas, al tiempo que, de manera clara y lógica, contribuya a crear un branding acorde con las necesidades del presente, tal y como demuestran estudios e informes como el realizado por Sandra Virginia Contreras (2012, pp 105-136)

\section{Diseño de contenidos}

Con el fin de asegurar este conocimiento y manejo de las estrategias visuales, y su adecuación a las prerrogativas necesarias de la industria del diseño y la publicidad en la cultura actual, se ha establecido un programa específico de análisis y enseñanza comparativa entre las asignaturas de Estética y Cultura Visual y Diseño, por las que poner en valor los distintos elementos compartidos entre ambas como lenguajes visuales, y su correcta conceptualización (Català,2005).

Para esta puesta en común entre ambas asignaturas se ha realizado un planteamiento docente en el que ambas debían quedar vinculadas desde tres puntos de vista: planificación de la asignatura, en la que se contemplara la necesaria vinculación curricular de la misma, y el aporte teórico y práctico con el que cada una de las asignaturas del grado debía complementarse entre sí. La planificación docente en la que las referencias a los métodos, discursos, análisis y prácticas del diseño, tanto desde una importancia histórica (con referencias ineludibles al trabajo de la 
Presol Herrero, A. y Pérez Manzanares, J.

La necesidad de la educación estética para la formación en diseño gráfico: una propuesta metodológica.

vanguardia rusa, Bauhaus, Op-Art o Cartelismo Publicitario) como parte de los discursos teóricos y críticos contemporáneos de carácter tanto formal como simbólico. Y por último, para comprobar la adecuación de los métodos y propuestas docentes en la implantación de las asignaturas en el grado, se ha realizado un cuestionario anónimo entre los alumnos del mismo, para comprobar el nivel de comprensión de la necesidad de vinculación y trasvase de información compartida por ambas asignaturas.

La selección del modelo de encuesta, tanto desde un punto de vista teórico (realizada el 11 de diciembre), como práctico (encuesta realizada el 21 de enero), acercaba el interés por conocer los valores cuantitativos ratificados por la recogida de los datos. Se trataba, de este modo, tanto de refrendar y poner en cuestión los procedimientos e hipótesis como, valiéndose de las mismas, $\mathrm{y}$, siguiendo el modelo de Dillon, Maddle y Firtle, acercarse a un modelo de evaluación de la toma de muestras cercano a los procedimientos de investigación de mercados relacionados con la investigación publicitaria. La elección de los plazos en la que la misma se realizó, justo en el momento de finalización de la asignatura de Estética y Cultura Visual (encuesta teórica) y al inicio del desarrollo de la asignatura de Diseño (encuesta práctica) intentaba evitar el sesgo de aprendizaje en la realización de encuestas que pudiese aportar información previa a los participantes, condicionando así sus respuestas.

Con los objetivos y metodología presentes, tanto para el diseño de la docencia como para la evaluación de la hipótesis y resultados, la reorganziación de contenidos y materiales se ha asentado en los siguientes métodos y objetos de análisis:

1. Capacidades comunicativas de la imagen: Partiendo de las teorías generales sobre la imagen como forma de comunicación, se ha incidido en la necesidad de conocimiento y uso de las teorías de creación de mensajes comunicativos, atendiendo a las características semióticas y semiológicas de los mismos. Por medio de la Teoría de creación de mensajes audiovisuales, se ha analizado históricamente y en el presente la relación de los componentes formales (connotativos) y de significado (denotativos) de las imágenes, como parte inexcusable de la creación de mensajes cohesionados y eficaces.

2. Por medio de la aproximación histórica a las distintas formas y tecnologías visuales (desde los tradicionales dibujo y pintura a las formulaciones técnicas de la fotografía, el cine o las tecnologías digitales) se ha observado el modo en que la interpretación y creación de los mencionados mensajes comunicativos se han ido modificando y transformando en función de las siguientes necesidades;

Sociales. Teniendo en cuenta los cánones y la importancia que los cambios y contextos sociales han tenido en la comunicación audiovisual, se ha tratado de contemplar los mismos como parte necesaria del programa de enseñanza. Por medio de los mismos, los futuros profesionales han podido observar la importancia que la adecuación a las formas y contenidos propios de la actualidad puede tener la 
Presol Herrero, A. y Pérez Manzanares, J.

La necesidad de la educación estética para la formación en diseño gráfico: una propuesta metodológica.

utilización de unos u otros diseños de imagen, y la variedad de lecturas posibles a la que los mismos se pueden someter una vez introducidos en la denominada "iconosfera" contemporánea. Con el fin de poder controlar la recepción de los mensajes audiovisuales producidos de antemano, la formación técnica y el conocimiento del uso y circulación social de las imágenes en la cultura visual contemporánea se consideran fundamentales como parte de la formación.

Técnicas. Incidiendo en la necesidad de comprensión y análisis que las distintas formulaciones y avances de carácter técnico pueden tener en la creación y difusión de diseños y mensajes comunicativos de carácter visual. Por un lado, la perspectiva histórica les ofrecía, en este sentido, un múltiple catálogo de posibilidades y ejemplos de adecuaciones técnicas y semánticas, al tiempo que posibilitaba la aproximación a fórmulas, estilos y obras cuya capacidad comunicativa pudiesen contrastar con su utilización práctica en el marco de la creación de diseños propios.

Críticas. La interpretación de cada uno de los distintos apartados anteriores en función de la teoría e interpretación de carácter semiótico que ha acompañado su creación, difusión e interpretación, obliga al desarrollo de ciertas herramientas de carácter crítico e interpretativo de aproximación a la cultura visual, que posibilite un correcto uso en el diseño, producción y circulación de mensajes comunicativos audiovisuales. Se han observado los componentes deontológicos que la comunicación audiovisual posee desde el conocimiento y análisis de ciertas técnicas relacionadas con las representaciones desde el punto de vista del género y la identidad racial, así como desde el punto de vista de las implicaciones y posibilidades de difusión técnica por medio de los distintos canales disponibles, y la necesidad de la adecuación de las características técnicas de la creación de diseños a los métodos, públicos objetivos a que se dirigen, necesidades técnicas e implicaciones prácticas que es necesario conocer y controlar de antemano como profesionales de la comunicación publicitaria de carácter audiovisual (Mulvey, 2001; 365-377 y Mitchell, 2017).

\section{METODOLOGÍA}

En función de los objetivos propuestos, y para poder obtener datos objetivos contrastables con la hipótesis de necesidad de combinación transversal y complementaria de los aspectos teóricos y prácticos de las asignaturas de Estética y Cultura Visual y Diseño Gráfico, se decidió poner a prueba y evaluar la implantación de la formación en estética y cultura visual antes de trabajar con las herramientas de diseño. La misma, se realizó durante el curso 2019/2020 por parte de los alumnos del grado en Publicidad y Relaciones Públicas, así como los dobles grados en Marketing, Diseño y Comunicación Corporativa y Organización de eventos.

En años anteriores, el plan de estudios no contemplaba la opción ni la necesidad de la formación previa en estética ni arte, como apoyo a la calidad docente y a la adquisición de las competencias digitales de los alumnos. En cuanto a las competencias y objetivos específicos, se decidió por dotar al alumno de la capacidad 
Presol Herrero, A. y Pérez Manzanares, J.

La necesidad de la educación estética para la formación en diseño gráfico: una propuesta metodológica.

de reunir e interpretar la información relevante, que les permitan evaluar y emitir juicios que incluyan el poder reflexionar sobre los temas relevantes de carácter social, científico e incluso ético. Para ello, se consideró la incorporación de la asignatura de Estética y cultura visual para favorecer la propuesta de adquisición de competencias específicas, entre las que se encuentra poder aplicar los conocimientos de una forma profesional y lograr alcanzar las competencias que suelen demostrarse por medio de la elaboración y defensa de argumentos y la resolución de problemas dentro de su área de estudio. Del mismo modo, se buscó, siguiendo argumentos como los expuestos por Freedman y Stuhr (2004; 818-820), realizar una adaptación curricular de las nuevas tecnologías de la creación visual y contemplando las nuevas necesidades sociales y culturales, así como reunir e interpretar los datos excelentes, que les permita emitir juicios que incluyan una reflexión sobre temas relevantes de índole social, científica o ética. Se trata, por tanto, de continuar con las propuestas que desde hace años abogan por una educación (especialmente orientada al territorio de la comunicación y las artes) en las que los conocimientos transversales "habiliten a los estudiantes de las sociedades democráticas para comprender y partcipar de las necesarias conversaciones culturales generadas por las artes visuales, el cine, así como el resto de prácticas creativas" (Gude,O., 2007; 10)

Por otra parte, respecto a la evaluación de los objetivos, se ha realizado un cuestionario sencillo compuesto por cuatro preguntas cerradas, dicotómicas y categorizadas sugeridas. La elección del cuestionario como herramienta de análisis se debió a que las preguntas concretas favorecían los resultados cuantitativos, fundamentales para cumplir los objetivos de estudio. Según contenido se pretende conocer la acción, intención e información sobre los valores relación entre las dos asignaturas. Con más de un mes de diferencia, se ha realizado el segundo cuestionario con cuatro preguntas con estructura similar al primer cuestionario, pero en esta ocasión, se ha proporcionado al encuestado, dos preguntas abiertas para de manera opcional, justificar la respuesta de algunas preguntas.

\section{Selección de la muestra}

Para la selección de la muestra se han tenido en cuenta todos los alumnos matriculados en primer curso del Grado en Publicidad y relaciones públicas y dobles grados de la Universidad Antonio de Nebrija (UAN). La muestra está compuesta por 45 alumnos matriculados en los grados señalados. El índice de participación en el primer cuestionario fue del 82,2 por ciento sobre el total y la respuesta del segundo bajó al 66,67 por ciento.

Al total de la muestra, se les envía los dos cuestionarios a través de la herramienta Forms de Microsoft en los diferentes periodos a través de los mails corporativos en periodos de tiempo diferentes. La primera fase de investigación se pasa en el mes de diciembre coincidiendo con el final de la asignatura de Estética y Cultura visual, y la segunda fase se pasa en febrero de 2020, una vez comenzada la asignatura de Diseño Gráfico. Destacar que se trata de alumnos de primer curso que aparecen en el portal en Servicio al Profesorado (SSP) como estudiantes en las listas de grupos. 
Presol Herrero, A. y Pérez Manzanares, J.

La necesidad de la educación estética para la formación en diseño gráfico: una propuesta metodológica.

\section{RESULTADOS}

La investigación consta de dos fases cualitativa y cuantitativa. La observación de contenidos y análisis de resultados obtenidos a partir de cuestionario.

\subsection{Fase cuantitativa:}

Con el fin de contrastar la necesidad teórica observada en la vinculación e introducción de la cultura visual y la estética junto al desarrollo formativo y profesional relacionados con la publicidad y el diseño, se elaboró un cuestionario con los alumnos de la asignatura "Estética y Cultura Visual", impartida en el primer curso de grado. Los resultados que se intentaban obtener y evaluar por medio del mismo, trataban de analizar el conocimiento previo de los alumnos, el nivel de implicación, relevancia de su formación en éstas áreas.

El primer cuestionario fue realizado el 11 de diciembre de 2019. Contó con una participación activa de 37 encuestados, de un grupo de 45 alumnos inscritos en la asignatura de grado. Por tanto, el $82,2 \%$ de los alumnos formó parte de dicha encuesta. Consideramos, en este período de la evaluación, que se trata de un porcentaje lo suficientemente amplio como para poder ser tomado en consideración como contraste y baremo de nuestra metodología y de los resultados obtenidos hasta el momento.

El cuestionario se concretó en tres preguntas a las que los participantes debían responder marcando opciones numéricas, y a las que podían sumar sus comentarios personales en caso de que no encontraran el necesario reflejo de su opinión personal, entre las respuestas ofrecidas. En todos los casos observados, el comentario de tipo personal ofrecía un refrendo de la valoración numérica obtenida, o no resultaba evaluable de cara a la investigación, al ofrecer comentarios valorativos de la asignatura que excedían el ámbito de la investigación y la toma de datos de la muestra.

Entre las preguntas planteadas en el cuestionario se quiere conocer la opinión personal que suscitó la asignatura de Estética y Cultura Visual como propia del grado, y su relación con el resto de asignaturas del curso.

A continuación, se ofrecía a los alumnos el listado completo de asignaturas del grado, de las cuales debían señalar aquellas opciones que consideraban que podían ajustarse a la respuesta correcta, y entre las que se incluía la propia asignatura en cuyo marco se realizaba la toma de datos. Por medio de este procedimiento, se intentaba realizar la misma de la manera más objetiva posible, contribuyendo a que los alumnos encuestados percibieran la distancia necesaria entre la materia y la vinculación con el resto de las asignaturas del grado con independencia del carácter. 
Presol Herrero, A. y Pérez Manzanares, J.

La necesidad de la educación estética para la formación en diseño gráfico: una propuesta metodológica.

En la recogida de la información y con el interés de obtener la mayor respuesta, se utiliza la herramienta Forms de Microsoft. Con un índice de respuesta de treinta y siete resultados, con 7,41 puntos de promedio. Los resultados muestran, que existe un $0 \%$ de los usuarios que completaron el cuestionario (0 de 37) respondió correctamente a esta pregunta.

A continuación, se exponen los resultados de las relaciones posibles entre la asignatura de Estética y Cultura Visual con el resto de las asignaturas del Grado y el número de respuestas:

\section{Asignaturas Grado}

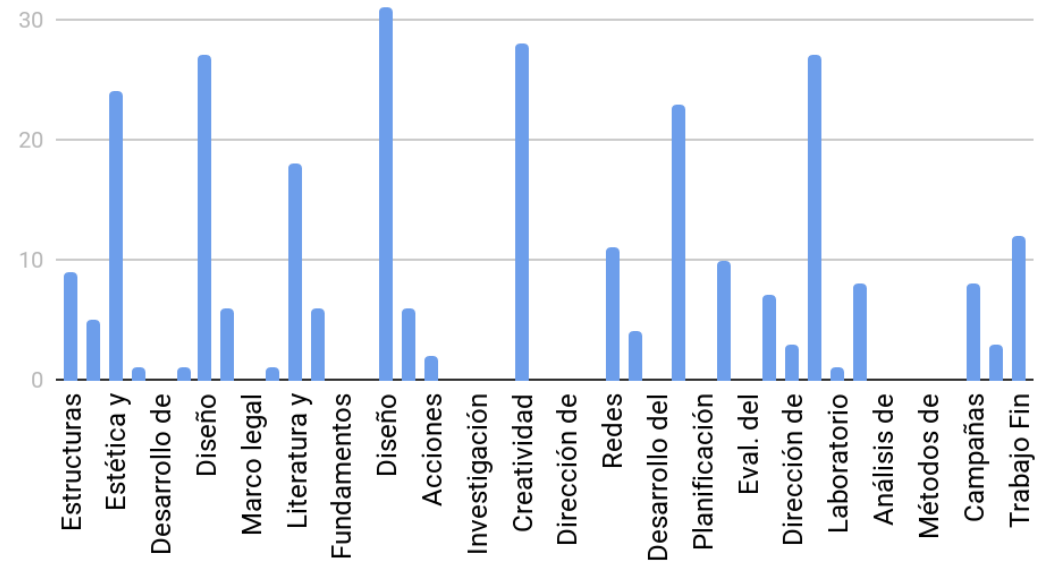

Gráfico 1: Respuesta relación de asignaturas con Estética y Cultura visual Fuente: Elaboración propia

El análisis de los resultados obtenidos en el cuestionario, destacan que existen más de dieciocho asignaturas, que los alumnos no encuentran relación con la asignatura de Estética y Cultura Visual, de diferentes cursos del Grado. Por el contrario, los resultados muestran que la percepción entre la razón de ser de la transmisión de los valores estéticos está íntimamente relacionada con las cuatro asignaturas de diseño (Diseño Gráfico, Diseño Publicitario, Diseño web y Dirección de Arte) y Creatividad Publicitaria.

Parece que las relaciones perceptuales establecidas a priori, responden a un conocimiento precoz y una escasa experiencia, en la que la hipótesis de partida sobre la que se basa la propuesta, coincide en primer término.

Los resultados denotan la necesidad de entrar a valorar las competencias específicas e incluso contrastarlos con las encuestas de satisfacción del profesor y resultados de la evaluación ordinaria, incrementaran la eficacia de la investigación. 
Presol Herrero, A. y Pérez Manzanares, J.

La necesidad de la educación estética para la formación en diseño gráfico: una propuesta metodológica.

Se han agrupado por orden ascendente y en intervalos de cinco respuestas. Hay dos grupos con las asignaturas que no tuvieron ninguna respuesta y los opuestos, con más de veinticinco asociaciones.

La mayor asociación de respuestas coincide con las asignaturas de Diseño Gráfico, Diseño Publicitario, Creatividad Publicitaria, Diseño web y Dirección de Arte.

En contraposición a estas respuestas, entre las asignaturas que destacan por no haber sido asociadas con la asignatura de Estética y Cultura Visual, se encuentran Competencias profesionales, Marco Legal o Estadística Aplicada, incluso asignaturas más relacionadas con la profesión como Investigación de audiencias, pero que desmarcan claramente del concepto de estética visual.

En la segunda encuesta, realizada el 21 de enero de 2020, el primer día de clase del segundo semestre del curso, se obtuvo una respuesta de 30 sobre un total de 45 alumnos, matriculados en primero curso y en las asignaturas objeto de aprendizaje. Es por ello, que el $66,67 \%$ de los alumnos formó parte de dicha encuesta, siendo por tanto un porcentaje inferior al primero, pero suficientemente amplio como para poder considerar los resultados obtenidos.

El cuestionario consistía en seis preguntas, cuatro de ellas con cuatros respuestas de carácter obligatorio y dos abiertas, opcionales que permiten al entrevistado, completar la respuesta argumentado dos de las tres preguntas cerradas. La intención de este tipo de respuestas era conseguir información de carácter cualitativo que permitiera ampliar la información y por ello, interpretar los resultados.

Las preguntas planteadas en el cuestionario fueron dirigidas al valor de la imagen de marca a partir de los conocimientos adquiridos en la asignatura del primer semestre. Fueron planteadas diferentes cuestiones estética. En primer lugar, se pregunta sobre la paleta de colores (claro, llamativos, con alto nivel de contraste o en escala de grises); el propósito es segmentar a los sujetos por grupo de preferencia. Con los resultados, se deduce que más del 50\% de la muestra (17 personas) prefieren los colores claros y relajantes, mientras que el $6 \%$ que prefiere los colores llamativos y estridentes.

No obstante, con el fin de recoger la máxima información, la siguiente pregunta permite argumentar, opcionalmente, la respuesta de la primera pregunta. Por su parte, solo un $20 \%$ de personas deciden explicar las razones de su elección; entre las respuestas destacan que son colores con los que suele vestir, transmiten calma, refuerzan y resaltan, fáciles de combinar entre sí, entre otros.

Además se propone un acercamiento a códigos morfológicos, posicionales, tipográficos, entre otros, que definen rasgos del usuarios y valores simbólicos, relevante para la investigación. Entre las respuestas se encuentra la preferencia por las formas angulosas, redondeadas, imágenes reinterpretadas o tipografías, pudiendo razonar la respuesta. La mitad de los encuestados prefieren las formas 
angulosas y expresivas, frente a los que prefieren las formas redondeadas. Destaca el bajo índice de respuesta relacionada con la tipografía con un 3,3\%. Entre las respuestas relativas a la pregunta tres, resaltan criterios como la originalidad, la expresión y su evolución.

La descripción de la función principal del logotipo y/o imagen de marca se enmarca en la persuasión, la comunicación, la estética o la estética junto con la función comunicativa.

Esta pregunta sugerida, ratifica uno de los puntos de partida de la investigación, en la que más del $50 \%$ de los sujetos relacionan la función principal de un logotipo o marca con la función estética y comunicativa. Mencionar que no hay ninguna respuesta que vincule la función decorativa con la imagen de marca.

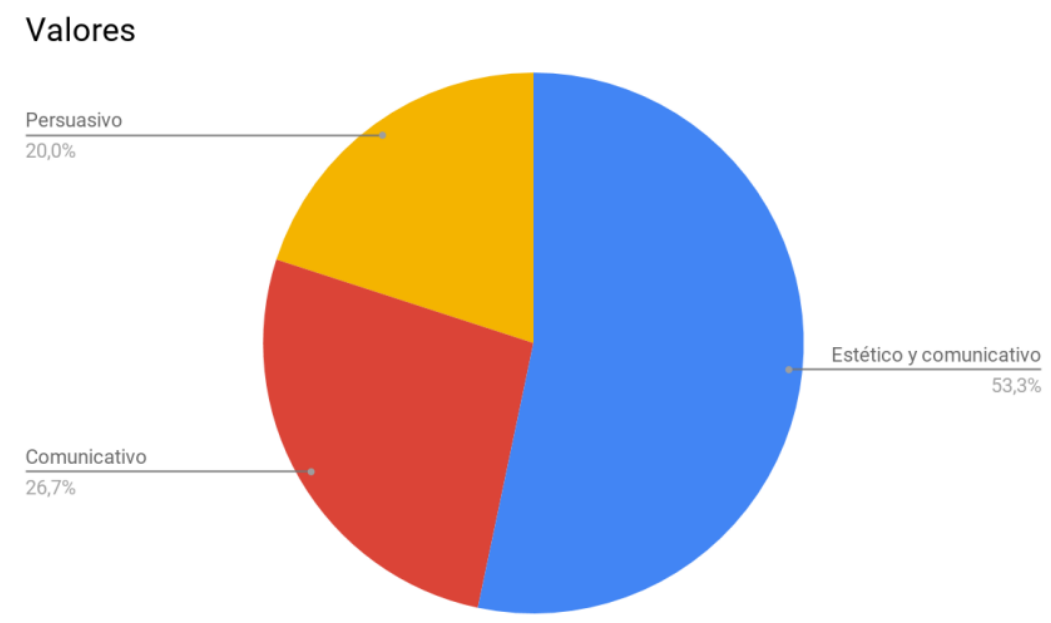

Gráfico 2: Respuesta función principal del logotipo y/o imagen de marca Fuente: Elaboración propia

La última parte del cuestionario analiza la interpretación en la evolución de la identidad corporativa de una marca $N B A^{2}$; A partir del pictograma, el sujeto elige la razón por la que cree se ha realizado el cambio. Entre las respuestas se pretende vincular con un valor social de lo "americano", o una intención más dirigida como es por la necesidad de establecer una analogía con el deporte, subrayando la idea de la figura estilizada y vertical. En contraposición, desde un punto de vista más funcional, el cambio podría responder al objetivo de conseguir un logotipo más corto o incluso dar mayor importancia al icono. Con un 53\% de respuesta en las que se asocia la modificación de la identidad visual de la marca NBA a la necesidad de ajustar el logotipo a la idea de estilización y verticalidad del propio deporte. Las otras tres respuestas se encuentran en el $20 \%$ sobre el total.

2 National Basketball Association 
Presol Herrero, A. y Pérez Manzanares, J.

La necesidad de la educación estética para la formación en diseño gráfico: una propuesta metodológica.

\section{CONCLUSIONES Y DISCUSIÓN}

A partir de la experiencia basada en el objetivos de aprendizaje y de las necesidades de conocimiento de los alumnos, se produce un cambio en la conducta que va más allá de la experiencia. El diseño de un plan de actuación basado en la participación activa entre el profesor y el alumno, garantiza la eficiencia de los resultados de aprendizaje .

Por su parte, observando las necesidades detectadas para la fusión y coordinación de ambas materias en la formación del grado en Publicidad y Relaciones Públicas, se han obtenido los siguientes resultados en la primera fase de investigación:

Validación de metodologías transversales implantadas: Tanto a través de la puesta en práctica docente, como corroborada por las encuestas realizadas a los alumnos. Comprobamos que, a pesar de la extrañeza que materias como la estética podían ofrecerles de manera inicial, al superar el perfil técnico que inicialmente asociaban a la formación de grado, una vez desarrollado el aprendizaje cambia tanto la percepción sobre la misma, como la vinculación con el resto de asignaturas del grado. Es llamativo que la vinculación se haya dado más con asignaturas de carácter práctico (Diseño) que con asignaturas similares de carácter teórico (Literatura y creación), lo cual complementa la opción e impresión de la transversalidad de sus objetivos y métodos como uno de los valores a destacar de la materia.

Constatación de la interpretación de las capacidades comunicativas de la imagen: Lejos de ser el elemento cotidiano y ordinario al que la cultura visual (en su carácter práctico, y no formativo) nos acostumbra como espectadores, los alumnos y alumnas del grado han podido comprobar, interiorizar y valorar de manera crítica la importancia que los mensajes comunicativos tienen como elementos necesarios de la comunicación contemporánea. Esto es lo que puede interpretarse del número de implicaciones que encuentran en los cuestionarios realizados con asignaturas del grado, y específicamente con aquellas que no se encuentran exclusivamente limitadas con lo visual. Es llamativo, y especialmente relevante para nuestra investigación, que los resultados ofrecidos por las encuestas realizadas ofrezcan coordinaciones con aquellas materias que se encuentran vinculadas con los elementos de carácter discursivo, formal y crítico. Incluimos en estos apartados aquellos destinados tanto a la correcta fundamentación icónica de labores de branding y creación de imagen, como a la correcta y eficaz transmisión de los mismos en la elaboración de diseños y marcas de carácter audiovisual.

Formación icónica. Acudiendo a ejemplos de carácter histórico, los alumnos parecen haber asimilado dos características fundamentales de la cultura icónica, especialmente aplicables en las labores de diseño y comunicación audiovisual: la necesidad de atención a las características histórico-sociales (incluyendo los movimientos relacionados con las características ideológicas, políticas, sociales o estilísticas que mayor resonancia e impacto social puedan tener en el mundo de la comunicación) como elementos de necesaria evaluación, utilización y puesta al día en 
Presol Herrero, A. y Pérez Manzanares, J.

La necesidad de la educación estética para la formación en diseño gráfico: una propuesta metodológica.

los propios elementos de creación comunicativa. Asimismo, por medio de ellos queda puesto de manifiesto la necesidad (tal y como se contemplaba inicialmente en la fusión de contenidos e introducción de nuevas materias docentes) de generar cauces de comunicación transdisciplinares, y que vinculasen características de carácter general con necesarias evaluaciones de carácter "medial", incluso desde el punto de vista temporal.

De este modo, comprobamos que los alumnos han asumido el carácter culturalmente "universal" (en función de las coordenadas espacio-temporales dadas) de ciertas fórmulas de comunicación y diseño vinculadas la tradición occidental, al tiempo que las capacidades para poner las mismas en cuestión en función de los objetivos concretos a conseguir mediante sus propias estrategias interpretativas y comunicativas.

Por último, y de manera fundamental, las muestras tomadas han venido a comprobar el modo en que elementos gramaticales propios del diseño alcanzan un valor comunicativo que no era percibido de manera inmediata, y ha quedado ligado a la interpretación formal de manera indefectible a partir del respaldo teórico previo. Formulaciones y elementos como la composición, la línea, el color o, de manera radicalmente importante, el diseño que acompaña a todas ellas, no puede ser entendido como un elemento o fórmula de comunicación aislado. La experiencia docente a que ha dado lugar la fusión y complicidad entre ambas asignaturas asegura, como quedó claramente puesto de manifiesto en el segundo cuestionario realizado, que los alumnos poseían tanto la intuición como una la base metodológica necesaria para comprender cómo los elementos formales asociados a las estrategias de diseño y branding podían valerse de elementos relacionados con la composición visual clásica - o contemporánea, pero vinculada a sus valores formales-, para potenciar la enunciación y transmisión de los elementos comunicativos.

De tal manera, y como conclusión final, los resultados obtenidos en el cuestionario señalan la percepción positiva de los alumnos relativa a la decisión de incluir la asignatura de Estética y Cultura visual, después de haberla cursado y antes de empezar el segundo semestre, comprendiendo la vitalidad del papel teórico que la misma comparte con asignaturas vinculadas a ella de carácter práctico. A priori, parece que las respuestas coinciden con el propósito del cambio; se entiende que el estudio está "vivo" y será evaluado de nuevo, una vez finalizado el segundo semestre de primer curso, pudiendo ampliarse a un segundo estadio de esta evaluación, que emplazaríamos al periodo final del grado. Con estas nuevas tomas y muestras intentaremos completar el resultado de la información obtenida, para poder interpretar el valor e importancia que otorgan a la materia como instrumento de comprensión y análisis en relación con la formación completa recibida. Con ello, además, pensamos quedaría garantizado de manera mucho más efectiva el rigor de su observación.

El interés final de los autores, que creemos haber resuelto de manera satisfactoria en este primer estadio de implantación y evaluación inicial de los resultados 
Presol Herrero, A. y Pérez Manzanares, J.

La necesidad de la educación estética para la formación en diseño gráfico: una propuesta metodológica.

obtenidos, reside en el desarrollo de una propuesta metodológica basada en un método de enseñanza transversal impuesto por la situación actual en la que la enseñanza sea también transversal, en el que la difusión del conocimiento sea comúnmente desarrollado y aprendido entre las asignaturas.

Como se ha mencionado, existe un problema real, que es la baja motivación por desarrollar una formación y educación visual de carácter histórico y teórico sobre el conocimiento. La propuesta educativa supone un cambio en el proceso de comunicación (Arroyo, 2012) y formación visual de carácter interdisciplinar y referencial, en el que tanto la teoría como la práctica jueguen un papel extenso en el desarrollo de las competencias vinculadas al alumno, en su formación teórica y en la posibilidad de implementación de sus aptitudes creativas y críticas en la elaboración de trabajos creativos de carácter personal. Trabajos cuya eficacia tanto en el plano formal como semántico sea reflejo del valor y dominio de la labor comunicativa que las competencias en materia de diseño y estética han podido aportar en la formación y excelencia de las estrategias comunicativas desplegadas por los futuros profesionales de la comunicación visual y las estrategias de creación de marca vinculadas a las mismas.

\section{REFERENCIAS}

Arroyo, R. G. (2012). Del boceto al diseño: la materialización del discurso visual en el diseño gráfico. Vivat Academia, (119), 42-57.

Berardi, Franco "Bifo". (2017), Fenomenología del fin. Sensibilidad y mutación conectiva. Buenos Aires, Caja Negra.

Català, J. M. \& Doménech, J. M. C. (2005). La imagen compleja: la fenomenología de las imágenes en la era de la cultura visual (Vol. 42). Univ. Autònoma de Barcelona.

Contreras, R. y Sandra, V. (2012) Strategic aesthetics in advertising campaigns : implications for art direction education. (Tesis Doctoral). Disponible en https:/ / eprints.qut.edu.au/53222/

Costa, J. (1992). Identidad Corporativa y estrategia de empresa. Visual: magazine de diseño, creatividad gráfica y comunicación, (27), 14-20.

Diaz de Rada, V. (2007), Tipos de encuestas considerando la dimensión temporal, Papers, (86), 2007

Dillon, W. R., Madden, T. J. y Firtle, N. H. (1994). Marketing research in a marketing environment. Illinois: Richard D. Irving.

Flusser, V. (2019) El universo de las imágenes técnicas. Elogio de la superficialidad. Buenos Aires, Caja Negra editores. 
Presol Herrero, A. y Pérez Manzanares, J.

La necesidad de la educación estética para la formación en diseño gráfico: una propuesta metodológica.

Freedman, K. y Stuhr, P. (2004) "Curriculum changes for the 21st century: visual culture in art education". En (Eisner y Day, 2004) Handbooks of research and policy in art education. Mahwah, Lawrence Eribaum, NJ, 815-828

Grado en Publicidad y Relaciones Públicas: Crea, participa y brilla en el Festival "Tocados por la Publicidad". En Universidad de Nebrija. Recuperado de https://www.nebrija.com/carreras-universitarias/publicidad-relacionespublicas/ consultado el 16 de enero de 2020

Gude, O. (2007) “Principles of Possibility: Considerations for a 21st-Century Art \& Culture Curriculum". Art Education, 1(60), ProQuest Central, 6-17

Las mejores agencias de publicidad del mundo. (2017). ReasonWhy. Recuperado de https://www.reasonwhy.es/actualidad/sector/mejores-agencias-de-publicidadmundo

Lipovetsky, G. y Serroy, J. (2015) La estetización del mundo. Barcelona, Anagrama.

Martinez Luna, S. (2019). Cultura Visual. La pregunta por la imagen. Vitoria, Sans Soleil.

Mirzoeff, Michael. (2003), Introducción a la cultura visual. Barcelona: Paidós.

Mitchell, W. J. T. (2017). ¿Qué quieren las imágenes? Sans Soleil.

Mulvey, L. (2001) Placer Visual y cine narrativo en Wallis, Brian (ed.) Arte después de la modernidad. Nuevos planteamientos en torno a la representación. Madrid, Akal.

nPeople Confidential and Propietary. (2018). La Agencia del Futuro. Recuperado de https://ipmark.com/wp-content/uploads/2018/05/Estudio-RESET_Agenciasde-Espa \%C3\%B1a.pdf

Jordá, M. T. P. \& Pujante, A. P. (2015). Publicidad y filosofía. Parecidos razonables. Vivat Academia, (132), 88-105.

Skowronek, H. (1970). Lernen und Lernfähigkeit, Munich.p11

Tavin, Kevin. "Seeing and being seen: Teaching visual culture to (mostly) non-art education students", The International Journal of Arts Education 7(2), 2009, 14-22

\section{AUTOR/ES:}


Presol Herrero, A. y Pérez Manzanares, J.

La necesidad de la educación estética para la formación en diseño gráfico: una propuesta metodológica.

\section{África Presol Herrero}

Doctora en Publicidad y Relaciones Públicas por Universidad Camilo José Cela. Licenciada en Ciencias de la Información por la Universidad Complutense de Madrid. Directora del Grado en Publicidad y Relaciones Públicas de la Facultad de Comunicación y Artes en Universidad Antonio de Nebrija. Profesora de Diseño Gráfico, Pensamiento creativo y Diseño Publicitario. Mi actividad docente e investigadora centrada en líneas de investigación: creatividad y diseño gráfico, nuevas tecnologías, imagen corporativa e innovación educativa. Con más de 800 horas de formación complementaria como docente, dirección y valoración de TFM y TFG, dirección de Grado y coordinación de asignaturas y títulos, cargos de gestión y varios proyectos de innovación educativa.

apresol@nebrija.es

Orcid ID: https:// orcid.org/0000-0002-7600-8231

Google Scholar: https://scholar.google.es/citations?user=DlhhhLcAAAAJ\&hl=es

Academia.edu: https:// nebrija.academia.edu/africaPresol

\section{Julio Pérez Manzanares}

Doctor en Historia del Arte por la Universidad Complutense de Madrid. Profesor asociado en Universidad Antonio de Nebrija, impartiendo las asignaturas de Arte Contemporáneo y Estética y Cultura Visual en los grados de Comunicación Audiovisual y Publicidad y relaciones públicas. Especialista en arte contemporáneo, historiografía, teoría de género y cultura visual, ha realizado en este ámbito diversas publicaciones y comisariados de exposición.

jperezman@nebrija.es

Orcid ID: https:// orcid.org/0000-0003-0450-2932 